\title{
NoTE
}

\section{Glucokinase-maturity onset diabetes mellitus in the young suggested by factory-calibrated glucose monitoring data: a case report}

\author{
Nao Nomura ${ }^{1)}$, Katsumi Iizuka ${ }^{1), 2), 3)}$, Eiichi Goshima ${ }^{4)}$, Kazuyoshi Hosomichi ${ }^{5)}$, Atsushi Tajima ${ }^{5)}$, \\ Sodai Kubota ${ }^{1), 3)}$, Yanyan Liu $^{1)}$, Ken Takao ${ }^{1)}$, Takehiro Kato ${ }^{1)}$, Masami Mizuno ${ }^{1)}$, Takuo Hirota ${ }^{1)}$, \\ Tetsuya Suwa' ${ }^{1)}$, Yukio Horikawa' ${ }^{1)}$ and Daisuke Yabe ${ }^{1,3), 6), 7)}$

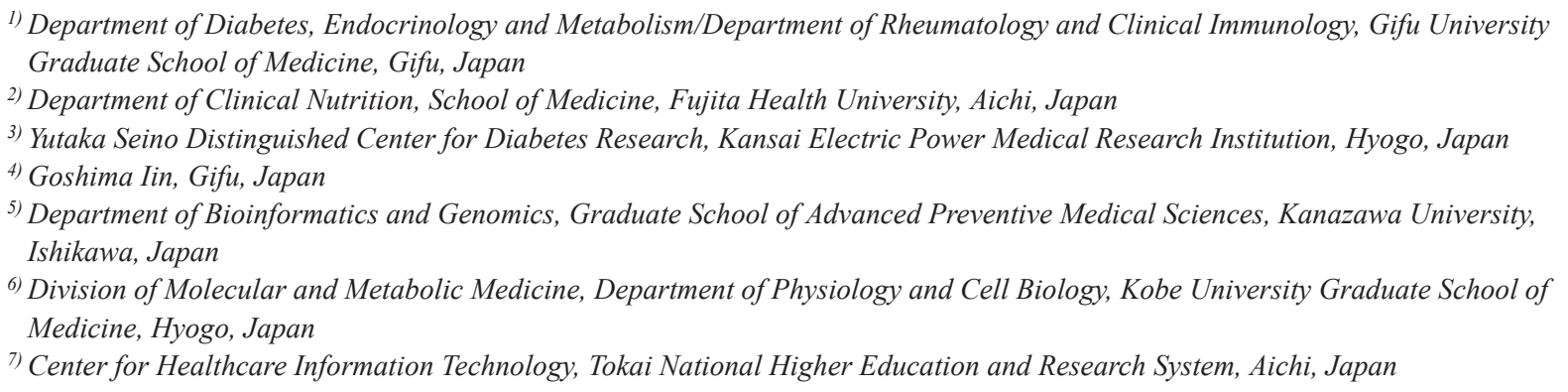

Abstract. Glucokinase has an important role in regulating glycolysis as a glucose sensor in liver and pancreatic $\beta$ cells. Glucokinase-maturity onset diabetes in young (GCK-MODY also known as MODY2) is caused by autosomal dominant gene mutation of the GCK gene; it is characterized by mild fasting hyperglycemia and small 2-h glucose increment during 75 g-oral glucose tolerance test (OGTT) as well as near-normal postprandial glucose variabilities. A 10-year-old girl with family history of diabetes visited her physician after being found positive for urinary glucose by school medical checkup. She received a diagnosis of diabetes based on the laboratory data: 75 g-OGTT (mild fasting hyperglycemia and small 2-h glucose increment) and factory-calibrated glucose monitoring (mild elevation of average glucose level and near-normal glycemic variability), which raised suspicion of GCK-MODY. She was then referred to our institution for genetic examination, which revealed a GCK heterozygous mutation (NM_000162: exon10: c.1324G>T: p.E442X) in the proband as well as in her mother and maternal grandmother, who had been receiving anti-diabetes medications without knowing that they had GCK-MODY specifically. GCK-MODY cases show incidence of microvascular and macrovascular diseases similar to that of normal subjects, and their glucose levels are adequately controlled without anti-diabetes drug use. Thus, early and definitive diagnosis of MODY2 by genetic testing is important to avoid unnecessary medication.

Key words: Glucokinase (GCK), Factory-calibrated glucose monitoring (FGM), Glucokinase-maturity onset diabetes mellitus in young (GCK-MODY), Maturity onset diabetes mellitus in young 2 (MODY2)

GLUCOKINASE (GCK) regulates glucose flux as a glucose sensor in pancreatic $\beta$-cells and liver [1]. Autosomal dominant gene mutation of the GCK gene is known to cause glucokinase-maturity onset diabetes in young (GCK-MODY, MODY2), which is is the most common cause of MODY (incidence 1:1,000 in Europe)

Submitted Aug. 21, 2021; Accepted Oct. 19, 2021 as EJ21-0526 Released online in J-STAGE as advance publication Nov. 19, 2021 Correspondence to: Katsumi Iizuka, MD, PhD, Department of Clinical Nutrition, School of Medicine, Fujita Health University, 1-98 Dengakugakubo, Kutsukake-Cho, Toyoake, Aichi 470-1192, Japan.

E-mail: katsumi.iizuka@fujita-hu.ac.jp
[2-4]. Patients with GCK-MODY have a defect in glucose sensing; glucose homeostasis is maintained at a higher set point resulting in mild, fasting hyperglycemia (97-149 $\mathrm{mg} / \mathrm{dL}$ [5.4-8.3 mmol/L]) with HbAlc 5.8$7.6 \%(40-60 \mathrm{mmol} / \mathrm{mol})$ [2]. In addition, these patients have glucose variabilities within normal range despite elevated fasting glucose levels $[5,6]$. Due to the lack of specific symptoms of GCK-MODY, it is often found by routine medical checkup at school or work [2-4]. It is also known that glucose levels are adequately controlled by healthy diet and exercise in GCK-MODY and that the incidence of microvascular and macrovascular diseases in GCK-MODY is similar to that of normal subjects [2]. 
Since GCK-MODY cases normally do not require antidiabetes drugs, a genetic test for the $G C K$ mutation is important for definitive diagnosis of GCK-MODY and avoidance of unnecessary anti-diabetes drugs [2, 3].

GCK is highly expressed in pancreatic $\beta$-cells and plays a pivotal role in glucose-induced insulin secretion (GIIS) by catalyzing conversion of glucose to glucose-6phosphate in pancreatic $\beta$-cells [1]. The GCK gene mutations found in GCK-MODY cases impairs glucose sensing of pancreatic $\beta$-cells and results in the increased set point for glucose-stimulated insulin secretion [2, 5]. GCK is also expressed in the liver and regulates hepatic glucose disposal and activates hepatic lipogenesis $[2,6]$; euglycemic clamp shows that suppression of hepatic glucose production is impaired in GCK-MODY by physiological insulin levels. Thus, combined defects of GCK in insulin secretion and hepatic insulin sensitivity contribute to the pathogenesis of GCK-MODY.
We recently attended to a case of GCK-MODY with GCK p.E442X mutation, in which $75 \mathrm{~g}$-oral glucose tolerance test (OGTT) and factory-calibrated glucose monitoring (FGM) initiated diagnosis of GCK-MODY.

\section{Case Presentation}

A 10-year-old girl with a family history of diabetes (Fig. 1) visited a family doctor after being found positive for urinary glucose at school medical checkup. She received a diagnosis of diabetes mellitus based on her laboratory data (HbA1c 6.7\% and fasting plasma glucose level $147 \mathrm{mg} / \mathrm{dL}$ ) (Table 1). During $75 \mathrm{~g}$ oral glucose tolerance test, her plasma glucose levels $(\mathrm{mg} / \mathrm{dL})$ were 147 [8.2 $\mathrm{mM}]$ at $0 \mathrm{~min}, 253$ [14.1 $\mathrm{mM}]$ at $30 \mathrm{~min}, 199$ [11.1 $\mathrm{mM}]$ at $60 \mathrm{~min}$ and $185[10.3 \mathrm{mM}]$ at $120 \mathrm{~min}$ and her serum insulin levels $(\mu \mathrm{U} / \mathrm{mL})$ were $5.6(38.9 \mathrm{pmol} / \mathrm{L})$ at $0 \mathrm{~min}$ and $34.5(239.6 \mathrm{pmol} / \mathrm{L})$ at $30 \mathrm{~min}$. Her

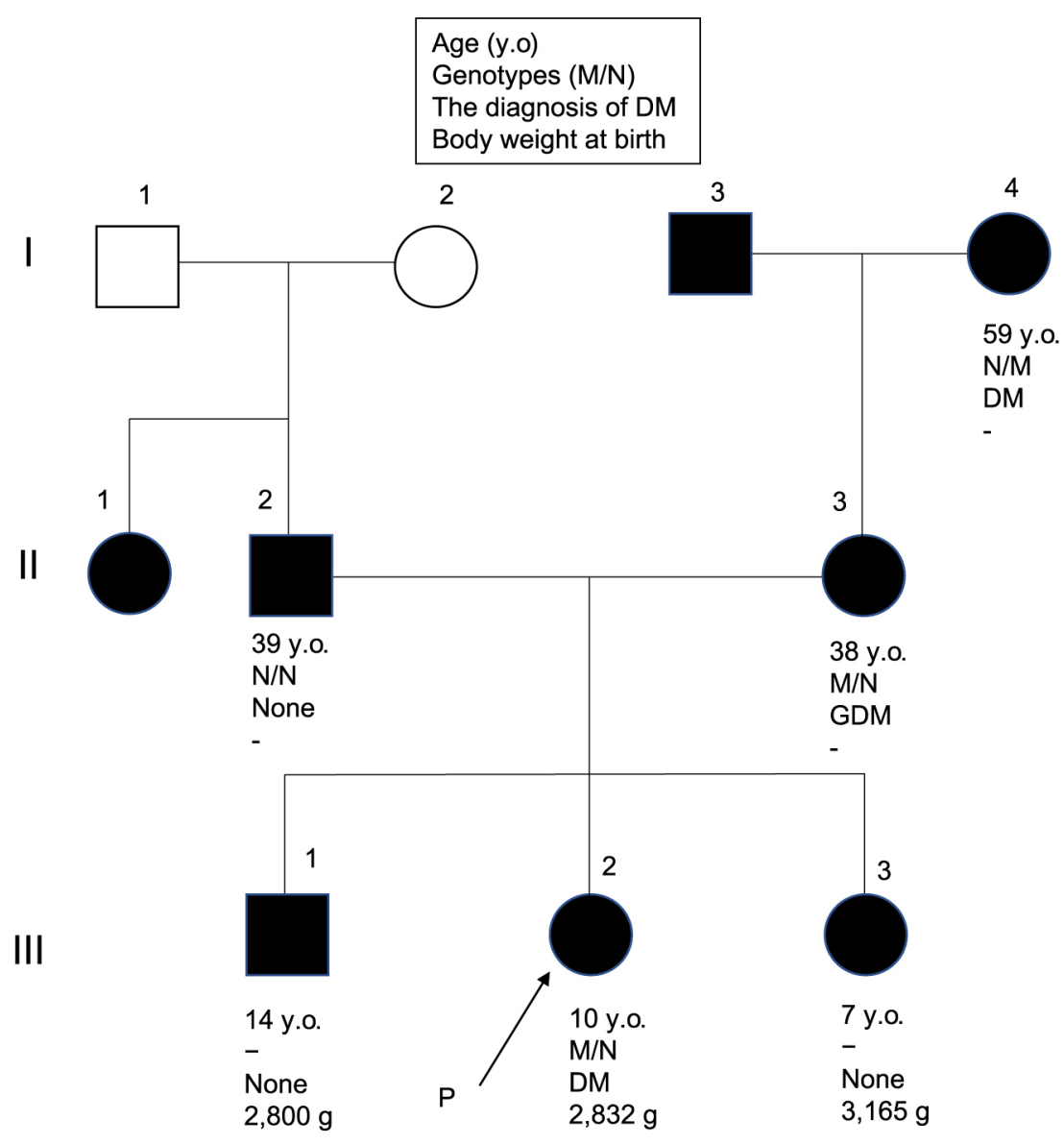

Fig. 1 Family tree of the patient. Squares, circles, and arrows indicate males, females, and proband, respectively. Family members, including her mother and maternal grandmother, had a history of diabetes. d. Diseased. N and M, wild type and p.E442X mutation alleles, respectively. Roman numerals on the left of the pedigrees indicate generation number, and the numbers below the symbols indicate the subject's number within each pedigree. The arrow shows the proband. Thus, III-2 indicates Proband. Body weighs at birth were 2,800 g (III-1), 2,832 g (III-2), and 3,165 g (III-3), respectively. Her mother and her grandmother had been maintaining $\mathrm{HbA} 1 \mathrm{c}<7 \%$ for several years. The current case and her families have no macro- or microangiopathies. 
insulinogenic index (II) and homeostatic model of assessment (HOMA)- $\beta$ and HOMA-insulin resistance

Table 1 Biochemistry, autoantibodies, hormones and urinalysis in the patient

\begin{tabular}{lc}
\hline Biochemistry & \\
\hline Glucose $(\mathrm{mg} / \mathrm{dL})$ & $147(80-110)$ \\
HbAlc $(\%)$ & $6.7(<6.2)$ \\
Total ketone $(\mu \mathrm{mol} / \mathrm{L})$ & $32(<74)$ \\
\hline Total cholesterol $(\mathrm{mg} / \mathrm{dL})$ & $196(130-219)$ \\
\hline Triglyceride $(\mathrm{mg} / \mathrm{dL})$ & $43(30-149)$ \\
\hline HDL-cholesterol $(\mathrm{mg} / \mathrm{dL})$ & $66(40-90)$ \\
\hline Lactate $(\mathrm{mg} / \mathrm{dL})$ & $10.2(3.0-17.0)$ \\
\hline Pyruvate $(\mathrm{mg} / \mathrm{dL})$ & $0.74(0.30-0.94)$ \\
\hline Autoantibodies & \\
\hline $\begin{array}{l}\text { Anti-glutamic acid decarboxylase antibody } \\
(\mathrm{U} / \mathrm{mL})\end{array}$ & $<5.0(<5.0)$ \\
\hline Islet antibody-2 $(\mathrm{U} / \mathrm{mL})$ & $<0.6(<0.6)$ \\
\hline Hormones & \\
\hline TSH $(\mu \mathrm{IU} / \mathrm{mL})$ & $1.06(0.54-4.54)$ \\
\hline Free $\mathrm{T}_{4}(\mathrm{ng} / \mathrm{dL})$ & $1.36(0.97-1.72)$ \\
\hline Insulin $(\mu \mathrm{U} / \mathrm{mL})$ & $5.6(2.2-12.4)$ \\
\hline C-peptide $(\mathrm{ng} / \mathrm{mL})$ & $1.3(1.1-4.4)$ \\
\hline Urinalysis & $(-)$ \\
\hline Glucose & $(-)$ \\
\hline Protein & $(-)$ \\
\hline Ketone & \\
\hline Albumin $(\mathrm{mg} / \mathrm{gCre})$ & \\
\hline & \\
\hline
\end{tabular}

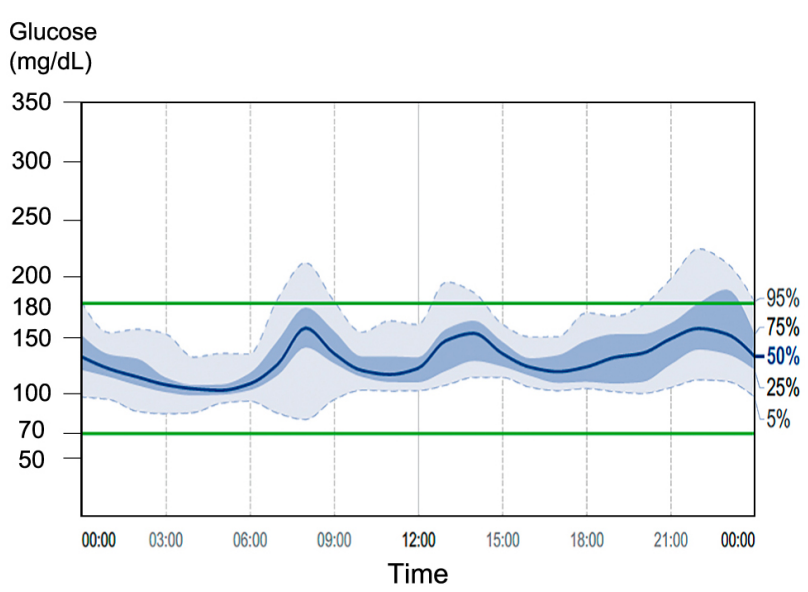

Fig. 2 Daily glucose profile. The daily glucose profile was monitored for 14 days using a factory-calibrated glucose monitoring system (Freestyle Librepro ${ }^{\mathrm{TM}}$, Abbot, Japan). Data represent medians of 10-90 percentiles.
(IR) were $0.27,24.4$ and 2.03, respectively. Her fasting C-peptide and C-peptide-to-glucose ratio were $1.3 \mathrm{ng} / \mathrm{mL}$ [0.43 nmol/L] and 0.88 , respectively. Her anti-glutamic acid decarboxylase antibody, islet antibody-2, and anti-insulin autoantibody were all negative. Factorycalibrated glucose monitoring (FGM) revealed that her average glucose level and glycemic variability (CV\%) were $134 \mathrm{mg} / \mathrm{dL}$ and $22.2 \%$ [normal range of average glucose and glycemic variability (mean \pm SD); 99 $\pm 7 \mathrm{mg} / \mathrm{dL}$ and $16 \pm 3 \%$, respectively] (Fig. 2) [7]. Fasting hyperglycemia and near-normal glucose variabilities led her family doctor to suspect GCK-MODY, who then referred the patient to our institution for genetic examination.

Upon admission, her height, body weight, and body mass index were $122 \mathrm{~cm}(-2 \mathrm{SD}), 23 \mathrm{~kg}(-2 \mathrm{SD})$, and 15.1, respectively. Her HbA1c was $6.7 \%$ [50 mmol/mol IFCC], and her 2hr-postprandial levels of plasma glucose, serum insulin, and serum C-peptide were $140 \mathrm{md} / \mathrm{dL}$ [7.8 mM], $22.1 \mu \mathrm{U} / \mathrm{mL}[153.5 \mathrm{pmol} / \mathrm{L}]$ and $2.6 \mathrm{pg} / \mathrm{mL}$ [0.86 nmol/L], respectively. Our genetic testing for MODY-related genes [8] of the patient and her family members found a heterozygous $G C K$ mutation ( $G C K$ : NM_000162: 10: c.1324G > T: p.E442X) in the proband (III-2), mother (II-3), and maternal grandmother (I-4); we concluded that our patient, her mother and maternal grandmother all had GCK-MODY. Consistent with other GCK-MODY cases, our patient's HbA1c was adequately controlled by healthy diet and exercise without use of anti-diabetes drugs.

We obtained approval for this study from Gifu University Graduate School of Medicine (Approval number 29-191). Genetic testing was carried out after counseling by a clinical genetic specialist using the assay previously described ${ }^{7}$. Written informed consent for genetic tests and publication was obtained.

\section{Discussion}

We treated a case of GCK-MODY that resulted from heterozygous GCK mutation (GCK: NM_000162: exon10: c.1324G>T: p.E442X).

GCK-MODY underlies 23-65\% of incidental hyperglycemia in children and its incidence is $1: 1,000$ in Europe [2]. While the rate in Japan is undetermined, it has been reported that it is similar to or higher than that of MODY3 [3]. It is known that glucose levels are adequately controlled by healthy diet and exercise in GCKMODY cases and that the incidence of microvascular and macrovascular diseases in GCK-MODY cases is similar to that of normal subjects [2]. It is also documented that average glucose levels are slightly elevated without affecting glucose variabilities in GCK-MODY 
cases $[5,6]$. Approximately $70 \%$ of GCK-MODY cases have a 2 -h glucose increment $\leq 54 \mathrm{mg} / \mathrm{dL}$ [3.0 mM] during 75 g-OGTT [9]. Our patient was finally diagnosed as GCK-MODY owing to her family doctor's suspicion of MODY2 based on her 75 g-OGTT (mild fasting hyperglycemia, $147 \mathrm{mg} / \mathrm{dL}$ [8.2 mM], small 2-h glucose increment $(38 \mathrm{mg} / \mathrm{dL}[2.1 \mathrm{mM}]$ ), and FGM data (mild elevation of average glucose level to $134 \mathrm{mg} / \mathrm{dL}[7.4$ $\mathrm{mM}]$ ) with near-normal glycemic variability, 22.2\%). Thus, her mother and maternal grandmother had been receiving anti-diabetes medications without knowing that their diabetes was caused by the $G C K$ mutation. Earlier diagnosis of GCK-MODY by genetic testing is therefore important to avoid unnecessary medication.

GCK-MODY is characterized partly by impaired glucose-sensing of pancreatic $\beta$-cells. GCK, which is mutated in GCK-MODY, plays a pivotal role in glucoseinduced insulin secretion (GIIS) by catalyzing conversion of glucose to glucose-6-phosphate in pancreatic $\beta$ cells $[1,10]$. It is known that glucose sensing of pancreatic $\beta$-cells in GCK-MODY cases, resulting in an increased set point for glucose-stimulated insulin secretion (healthy individuals, 99-108 mg/dL [5.5-6.0 mM] vs. GCK-MODY cases, $117-135 \mathrm{mg} / \mathrm{dL}$ [6.5-7.5 mM]) [5]. Consistently, our patient showed reduced insulin secretion relative to the fasting glucose levels (HOMA- $\beta$, $22.4 \%$ and C-peptide-to-glucose ratio, 0.88 ). We recently reported that L-arginine binds to GCK and increases production of glucose-6-phosphate, thereby enhancing GIIS [10]. Importantly, the GCK p.E442X mutation, the same mutation as that in the current case, was found to interfere with L-arginine binding to GCK, thereby impairing L-arginine-stimulated GIIS [10]. Although we did not perform iv L-arginine tolerance test, it is likely that our patient had reduced insulin secretion in response to iv Larginine load.

It has been shown that hepatic GCK plays an important role in maintaining glucose homeostasis [1-12]. Pancreatic $\beta$-cell-specific disruption of the Gck gene in mice reduces by half the hyperglycemia seen in mice deficient of the Gck gene globally [11]. Notably, mice with liverspecific disruption of the Gck gene exhibit fasting hyperglycemia, impaired glucose tolerance, and lower hepatic glycogen contents $[11,12]$, suggesting a critical role of hepatic GCK in the pathogenesis of MODY2. Indeed, it was demonstrated by euglycemic clamp that suppression of hepatic glucose production is impaired in MODY2 cases by physiological insulin levels ${ }^{2}$. While we did not perform euglycemic clamp experiment, hepatic insulin resistance was suggested based on her HOMA-IR (2.03). Several lines of evidence indicate that oral L-arginine administration activates GCK and improves hepatic insulin resistance [13-15]. It is thus thought that the GCK
p.E442X mutation found in MODY2 might diminish Larginine's effects by interfering with its binding to and activating GCK; we did not perform oral arginine loading experiment in our current patient.

The relationship of GCK mutations in mother and fetus with baby's birthweight has been discussed previously [16]. When both mother and fetus have GCK mutation, baby's birthweight is normal [16]. In contrast, when only mother and not fetus has GCK mutation, baby's birthweight is heavier than normal [16]. It is therefore recommended that the mother should receive insulin therapy to avoid fetal abnormalities in the latter condition [16]. The current case's mother was diagnosed with gestational diabetes mellitus and received insulin therapy for the first time when she became pregnant with her younger sister (III-3). Because the current case's mother did not receive insulin therapy during the pregnancy of the proband (III-2) or her brother and her brother (III-1) and younger sister (III-3) did not receive genetic tests, we cannot estimate any effects of insulin therapy during pregnancy on birthweight.

FGM is widely used to evaluate average glucose levels and glycemic variability both in patients with type 1 and type 2 diabetes on multiple daily insulin injection therapy in Japan. As seen in the current case, FGM can be used to screen GCK-MODY cases prior to genetic testing; the patients show elevated average glucose levels but normal glucose variability.

In conclusion, we report a case of GCK-MODY due to the mutation GCK: NM_000162: exon10: c.1324G>T: p.E442X, in which a daily glucose profile unique to GCK-MODY (mild elevation of average glucose level and near-normal glycemic variability) was first noted by FGM.

\section{Acknowledgments}

The authors are grateful to the patient for her contribution to this study. The authors also thank J. Kawada, H. Tsuchida and M. Kato for their technical assistance, and M. Yato, Y. Ogiso, and M. Nozu for secretarial assistance.

\section{Funding}

This work was supported by grants from the Japan Society for the Promotion of Sciences [20K11645 (K.I.), 20K19673 (Y.L.), 21K19504 (D.Y.)], the Japan Agency for medical research and development [JP20ek0210123s0602 (D.Y.)], Yakult Bio-Science Foundation (K.I.), and a Research Grant from Japan Diabetes Foundation and Costco Wholesale Japan Ltd (Y.H.). 


\section{Authorship}

All named authors meet the International Committee of Medical Journal Editors (ICMJE) criteria for authorship for this article, take responsibility for the integrity of the work as a whole, and have given their approval for this version to be published.

$\mathrm{NN}, \mathrm{KI}$, and DY contributed to the analysis, collection, and interpretation of data and writing of the manuscript. EG, KH, AT, SK, YL, KT, TK, MM, TH, TS, and $\mathrm{YH}$ contributed to the analysis, collection, and interpretation of data and critical revisions of the manuscript for important intellectual content. All authors approved the version to be published. KI is a guarantor of this work.

\section{Disclosures}

None of the authors has potential conflicts of interest associated with this research.

\section{Compliance with Ethical Guidelines}

All procedures performed in studies involving human participants followed the 1964 Helsinki declaration and its later amendments or comparable ethical standards. Informed consent was obtained from the patient.

\section{References}

1. Matschinsky FM, Wilson DF (2019) The central role of glucokinase in glucose homeostasis: a perspective 50 years after demonstrating the presence of the enzyme in islets of langerhans. Front Physiol 10: 148.

2. Chakera AJ, Steele AM, Gloyn AL, Shepherd MH, Shields B, et al. (2015) Recognition and management of individuals with hyperglycemia because of a heterozygous glucokinase mutation. Diabetes Care 38: 1383-1392.

3. Horikawa Y (2018) Maturity-onset diabetes of the young as a model for elucidating the multifactorial origin of type 2 diabetes mellitus. J Diabetes Investig 9: 704-712.

4. Stoffel M, Bell KL, Blackburn CL, Powell KL, Seo TS, et al. (1993) Identification of glucokinase mutations in subjects with gestational diabetes mellitus. Diabetes 42 : 937-940.

5. Byrne MM, Sturis J, Clément K, Vionnet N, Pueyo ME, et al. (1994) Insulin secretory abnormalities in subjects with hyperglycemia due to glucokinase mutations. J Clin Invest 93: $1120-1130$.

6. Velho G, Petersen KF, Perseghin G, Hwang JH, Rothman $\mathrm{DL}$, et al. (1996) Impaired hepatic glycogen synthesis in glucokinase-deficient (MODY-2) subjects. J Clin Invest 98: 1755-1761.

7. Shah VN, DuBose SN, Li Z, Beck RW, Peters AL, et al. (2019) Continuous glucose monitoring profiles in healthy nondiabetic participants: a multicenter prospective study. $J$ Clin Endocrinol Metab 104: 4356-4364.

8. Imaki S, Iizuka K, Horikawa Y, Yasuda M, Kubota S, et al. (2021) A novel RFX6 heterozygous mutation (p.R652X) in maturity-onset diabetes mellitus: a case report. J Diabetes Investig 12: 1914-1918.

9. Stride A, Vaxillaire M, Tuomi T, Barbetti F, Njølstad PR, et al. (2002) The genetic abnormality in the beta cell determines the response to an oral glucose load. Diabetologia 45: 427-435.

10. Cho J, Horikawa Y, Enya M, Takeda J, Imai Y, et al. (2020) L-Arginine prevents cereblon-mediated ubiquitination of glucokinase and stimulates glucose-6-phosphate production in pancreatic $\beta$-cells. Commun Biol 3: 497.

11. Postic C, Shiota M, Niswender KD, Jetton TL, Chen Y, et al. (1999) Dual roles for glucokinase in glucose homeostasis as determined by liver and pancreatic beta cell-specific gene knock-outs using Cre recombinase. J Biol Chem 274: 305-315.

12. Hayashi H, Sato Y, Li Z, Yamamura K, Yoshizawa T, et al. (2015) Roles of hepatic glucokinase in intertissue metabolic communication: examination of novel liverspecific glucokinase knockout mice. Biochem Biophys Res Commun 460: 727-732.

13. Gannon MC, Nuttall JA, Nuttall FQ (2002) Oral arginine does not stimulate an increase in insulin concentration but delays glucose disposal. Am J Clin Nutr 76: 1016-1022.

14. Piatti PM, Monti LD, Valsecchi G, Magni F, Setola E, et al. (2001) Long-term oral L-arginine administration improves peripheral and hepatic insulin sensitivity in type 2 diabetic patients. Diabetes Care 24: 875-880.

15. Monti LD, Valsecchi G, Costa S, Sandoli EP, Phan CV, et al. (2000) Effects of endothelin-1 and nitric oxide on glucokinase activity in isolated rat hepatocytes. Metabolism 49: 73-80.

16. Hattersley AT, Beards F, Ballantyne E, Appleton M, Harvey R, et al. (1998) Mutations in the glucokinase gene of the fetus result in reduced birth weight. Nat Genet 19: 268-270. 